\title{
Stability analysis in a Bertrand duopoly with different product quality and heterogeneous expectations
}

\section{Luciano Fanti • Luca Gori}

\begin{abstract}
We study the local stability properties of a nonlinear Bertrand duopoly with vertical differentiation and heterogeneous players with both covered and uncovered markets. In the former case, the unique pure strategy Nash equilibrium can undergo a flip bifurcation when the extent of consumer's heterogeneity increases. In the latter, the quality differential plays a preeminent role in determining stability of prices over time. Numerical evidence is provided to show the occurrence of endogenous fluctuations.
\end{abstract}

Keywords Bifurcation; Duopoly; Heterogeneous expectations; Price competition; Vertical differentiation

JEL Classification C62; D43; L13; L15

\section{Introduction}

It is observed that firms often supply differentiated products on the market, so that consumers face a large domain of varieties, which can sometimes unambiguously be ranked along some quality ladders. The focus of the present study is to analyse stability properties of a nonlinear duopoly (see Bischi et al., 2010) with price competition and vertical differentiation.

There exists an established literature that deals with problems of horizontal (quantity) and vertical (quality) differentiation of goods and services in static oligopoly games, essentially to rank equilibrium outcomes in both Cournot and Bertrand competition models. Studies that deal with the former type of product differentiation date back at least to the works by Dixit (1979), Singh and Vives (1984) and Vives (1985), while examples of the latter can be found in Gabszewicz and Thisse (1979), Shaked and Sutton (1982), Motta (1993), Wauthy (1996), Häckner (2000) and Correa-López and Naylor (2004). The findings of this literature represent a cornerstone of the oligopoly theory.

Another strand of literature on nonlinear oligopolies analyse several aspects of dynamic phenomena (e.g., local and global stability of dynamic systems). This literature is of increasing importance and makes expectations formation mechanisms different from the rational expectations paradigm relevant (see, e.g., Chiarella, 1986, 1990; Puu 1991, 1998; Agliari et al., 2006). As is known, the Nash equilibrium in a dynamic duopoly with standard linear demand and cost functions is stable if expectations of every firm are "naïve" (i.e., each firm expects that the value of the strategic variable set by the rival to maximise profits in the future period is equal to the current period one), as shown by Theocharis (1960) in a duopoly with quantity

\footnotetext{
L. Fanti

Department of Economics, University of Pisa, Via Cosimo Ridolfi, 10, I-56124 Pisa (PI), Italy

e-mail: lfanti@ec.unipi.it or fanti.luciano@gmail.com

tel.: +390502216369; fax: +390502216384

L. Gori (corresponding author)

Department of Law, University of Genoa, Via Balbi, 30/19, I-16126 Genoa (GE), Italy

e-mail: luca.gori@unige.it or dr. luca.goriegmail.com

tel.: +3901020995 03; fax: +390102095536
} 
competition à la Cournot (1838). However, if expectations of one or both firms are those of the type suggested by, e.g., Bischi et al. $(1998,1999)$, i.e. firms do not perfectly infer the decisions of competitors (bounded rationality) and increase/decrease their control variable in the current period depending on information given by marginal profits in the previous period (see Dixit, 1986; Bischi and Naimzada, 2000), then the equilibrium in a duopoly game with standard linear demand and cost functions may be destabilised when the reaction of every firm is large enough, as shown by Kopel (1996). In particular, the stability issue in duopoly games without vertical differentiation has been analysed, amongst others, by ( $i$ ) Agiza and Elsadany $(2003,2004)$, Zhang et al. (2007), Tramontana (2010) and Fanti and Gori (2012), as regards quantity competition, and (ii) Zhang et al. (2009) and Fanti and Gori (2011), as regards price competition.

However, at the best of our knowledge, the stability analysis in a duopoly with price competition in which firms provide products of different (say, high and low) quality, has not been so far tackled on. In this paper we aim to fill this gap by studying two distinct cases with both covered and uncovered markets: (i) the high-quality firm has bounded rational expectations and the low quality firm has naïve expectations; (ii) the low-quality firm has bounded rational expectations and the high-quality firm has naïve expectations. ${ }^{1}$ With regards to covered markets, we find that stability of prices in the long run depends only on the extent of consumer's heterogeneity. With regards to uncovered markets, the quality differential matters.

The remainder of the paper is organised as follows. Section 2 introduces the model. Under the hypothesis of covered market, Section 3 studies the conditions under which the unique pure strategy Nash equilibrium can loose stability in the case of heterogeneous expectations. Section 4 assumes uncovered markets and studies the dynamic properties of the twodimensional map in such a case. Section 5 concludes.

\section{The model (covered market)}

Following Tarola et al. (2011), we assume that: (1) there exist two firms ( $H$ and $L$ ) in the market providing goods and services of different quality to the customers; (2) it is unanimously believed that products of firm $H$ are of a higher quality than those of firm $L$; (3) the average cost of production is not affected by quality, and it is set to zero without loss of generality.

Consumers are identified by the parameter $\phi \in[a, b]$, where $0 \leq a<b$, which, by following an established literature (see Tirole, 1988; Motta, 1993), can be interpreted as "the marginal rate of substitution between income and quality" (Motta, 1993, p. 115). ${ }^{2}$ Then, $\phi$ measures the taste for quality of consumers, and it is assumed to be uniformly distributed with unit density (e.g., Motta, 1993; Liao, 2008), while the parameters $a$ and $b$ capture the extent of population heterogeneity. The larger the difference between $a$ and $b$, the higher the degree of heterogeneity amongst consumers. Preferences $(U)$ of consumer of type $\phi$ are described by the following expected utility function:

$$
U_{i}\left(\phi, p_{i}\right)=\phi u_{i}-p_{i}, \quad i=\{H, L\},
$$

\footnotetext{
1 It is usual in the literature on nonlinear oligopolies to assume firms with distinct expectations formation mechanisms (see, e.g., Leonard and Nishimura, 1999; Den-Haan, 2001).

${ }^{2}$ As pointed out by Motta (1993), by interpreting $\phi$ as a measure of the marginal rate of substitution between income and quality in a model where consumers' tastes heterogeneity is assumed, allows comparisons with models where there exists consumers' incomes heterogeneity (see, e.g., Gabszewicz and Thisse, 1979; Shaked and Sutton, 1982, 1983).
} 
where $u_{H}$ and $u_{L}$, with $u_{H}>u_{L}$, represent two indexes that capture the different quality (of products of firms $H$ and $L$ ) perceived by consumers, and $p_{i}$ is the price that consumers pay to buy product $i$, and then it represents the marginal willingness to pay to consume an amount of goods and services of quality $i$. Of course, the higher $u_{i}$, the higher utility $U_{i}$. Following Wauthy (1996), quality indexes are exogenous. Moreover, in order to guarantee that both firms set strictly positive prices at an interior equilibrium, we assume that: ${ }^{3}$

$$
a \in\left[0, \frac{b}{2}\right) \text {. }
$$

Let $\bar{\phi}$ be an index that identifies the consumer indifferent between purchasing products of high or low quality from firms $H$ and $L$ at the price $p_{H}$ and $p_{L}$, respectively. Such an index is obtained by equating $U_{H}\left(\phi, p_{H}\right)=U_{L}\left(\phi, p_{L}\right)$. Then, by solving the equation

$$
\phi u_{H}-p_{H}=\phi u_{L}-p_{L} \text {, }
$$

for $\phi$ we get:

$$
\bar{\phi}=\frac{p_{H}-p_{L}}{u_{H}-u_{L}},
$$

which depends on both the price differential and quality differential. The higher the former (latter), the higher (lower) the type of consumers with a taste for high-quality products. Then, consumers identified by $\bar{\phi}<\phi<b(a<\phi<\bar{\phi})$ purchase products of high (low) quality. Since the market is covered, $D_{H}\left(p_{H}, p_{L}\right)+D_{L}\left(p_{H}, p_{L}\right)=1$, with $D_{i}(\bullet)>0$ for $i=\{H, L\}$ (Gabszewicz and Thisse, 1979; Wauthy, 1996). Then, the demand functions to firms $H$ and $L$ are respectively given by:

$$
\begin{aligned}
& D_{H}\left(p_{H}, p_{L}\right)=b-\bar{\phi}=b-\frac{p_{H}-p_{L}}{u_{H}-u_{L}}, \\
& D_{L}\left(p_{H}, p_{L}\right)=\bar{\phi}-a=\frac{p_{H}-p_{L}}{u_{H}-u_{L}}-a .
\end{aligned}
$$

Profits of the $i$ th firm $\Pi_{i}(\bullet)=p_{i} D_{i}(\bullet)$, since average production costs are zero. Therefore, profits of firms $H$ and $L$ as a function of prices are given by:

$$
\begin{aligned}
& \Pi_{H}\left(p_{H}, p_{L}\right)=p_{H}\left(b-\frac{p_{H}-p_{L}}{u_{H}-u_{L}}\right), \\
& \Pi_{L}\left(p_{H}, p_{L}\right)=p_{L}\left(\frac{p_{H}-p_{L}}{u_{H}-u_{L}}-a\right) .
\end{aligned}
$$

The maximisation of Eqs. (6.1) and (6.2) with respect to $p_{H}$ and $p_{L}$ gives the following marginal profits:

$$
\begin{gathered}
\frac{\partial \Pi_{H}}{\partial p_{H}}=b-\frac{2 p_{H}-p_{L}}{u_{H}-u_{L}}, \\
\frac{\partial \Pi_{L}}{\partial p_{L}}=\frac{p_{H}-2 p_{L}}{u_{H}-u_{L}}-a .
\end{gathered}
$$

Therefore, the reaction- or best-reply functions of firms $H$ and $L$ are determined by equating Eqs. (7.1) and (7.2) to zero and solving for $p_{H}$ and $p_{L}$, respectively, that is:

\footnotetext{
${ }^{3}$ This will be clear from Eqs. (13) and (26) in the sequel of the paper. Note that this condition also guarantees that outputs and profits of both firms are positive at an interior equilibrium.
} 


$$
\begin{aligned}
& \frac{\partial \Pi_{H}}{\partial p_{H}}=0 \Leftrightarrow p_{H}\left(p_{L}\right)=\frac{1}{2}\left[p_{L}+b\left(u_{H}-u_{L}\right)\right], \\
& \frac{\partial \Pi_{L}}{\partial p_{L}}=0 \Leftrightarrow p_{L}\left(p_{H}\right)=\frac{1}{2}\left[p_{H}-a\left(u_{H}-u_{L}\right)\right],
\end{aligned}
$$

where $p_{H}-a\left(u_{H}-u_{L}\right)>0$ should hold.

In the next section we introduce dynamic elements into the static model described above, while also assuming that firms $H$ and $L$ have heterogeneous (namely, bounded rational and naïve) expectations about the price should be set in the future by the rival to maximise profits. Then, we study the local stability properties of the Nash equilibrium when the high-quality and low-quality firms are alternatively bounded rational and naïve.

Before starting with the analysis, however, it could be instructive to clarify the reasons why we have assumed players with heterogeneous expectations. First, since firms are heterogeneous because vertical differentiation exists into the model and then products of firms $H$ and $L$ are perceived of being of different quality by customers, it is relevant (in a dynamic setting) to see how every firm reacts to a change in the price sets by the rival when different expectations formation mechanisms are in existence. This because the response of one firm to a strategy played by its competitor is different depending on the adjustment mechanism used, and this makes the study of a model where players have heterogeneous expectations interesting in a dynamic setting. Indeed, in both cases we talk about myopic expectations. However, under the naïve rule we observe that one source of uncertainty exists in such a case: the naïve firm, in fact, does not know the behaviour of the rival but knows the shape of the market demand. It can then use this information through the reaction function to behave optimally over time. In contrast, under the bounded rational rule two sources of uncertainty are in existence: the bounded rational firm does not know both the behaviour of the rival but knows and the shape of the market demand. It estimates, therefore, its marginal profits to behave optimally over time, and, in a Bertrand duopoly, the optimal price set in the future period will be equal to the last period's one plus/minus something based on current marginal profits, which can be positive or negative. 4

Second, there exists an established branch of literature that investigates several aspects of dynamic games when firms are heterogeneous because of different expectations formation rules (see, e.g., Leonard and Nishimura, 1999; Den-Haan, 2001; Agiza et al., 2002; Agiza and Elsadany, 2003, 2004; Zhang et al., 2007; Tramontana, 2010; Fanti and Gori, 2012). Moreover, it is usual in both (static and dynamic) Cournot and Bertrand duopolies to study models with heterogeneous competitors (e.g., competitive wage versus non-competitive wage, products are substitutes or complements and so on).

Third, it is worth noting that by assuming both high-quality and low-quality firms to be bounded rational dramatically enriches the spectrum of dynamic outcomes with respect to the findings of this study. In particular, although the results as regards the effects on local stability of the parameter $a$ (under the covered market assumption) and the parameter $u_{L}$ (under the uncovered market assumption) are preserved, global bifurcations may also occur (e.g., coexistence of chaotic attractors) that cannot be observed in the case of heterogeneous expectations. In particular, the global behaviour of the noninvertible map when both players are bounded rational can be investigated through the study of critical curves, by which a two-

\footnotetext{
${ }_{4}$ As point out by Bischi et al. (1998, p. 561), in this class of models: "The dynamic game is based on the assumption that the two producers have not a complete knowledge of the market, hence they behave adaptively, following a bounded rationality adjustment process based on a local estimate of the marginal profit." We note that it is standard in this literature to refer to the player that expects the output/price of the competitor be equal to the last period's one as being "naïve", and to the player that uses the myopic adjustment mechanism (through marginal profits) described by Dixit (1986) and Naimzada and Bischi (2000) as being "bounded rational".
} 
dimensional area can be defined to give a bound to the amplitude of the trajectories. This topic is included in our future research agenda, and requires a technical paper to deeply investigate the mathematical properties of the map.

\section{Equilibrium and local stability with heterogeneous expectations}

\subsection{Covered market: case $B H / N L$}

In this section we assume that firm $H$ has bounded rational $(\mathrm{BH})$ expectations and firm $L$ has naïve (NL) expectations. Therefore, firm $H$ uses information on its profit at time $t=0,1,2, \ldots$ to increase or decrease prices at time $t+1$ according to the myopic mechanism described by Dixit (1986), that is:

$$
p_{H}(t+1)=p_{H}(t)+\alpha_{H} p_{H}(t) \frac{\partial \Pi_{H}(t)}{\partial p_{H}(t)},
$$

where $\alpha_{H}>0$ is a coefficient that captures the speed of adjustment of firm $H$ 's price with respect to a marginal change in profits when $p_{H}(t)$ varies, and $\alpha_{H} p_{H}(t)$ is the intensity of the reaction of the bounded rational player to a change in rival's price at time $t$. Therefore, $p_{H}(t+1)$ is increased or decreased depending on whether current marginal profits are positive of negative, respectively.

Using Eq. (9), and knowing that firm $L$ has naïve expectations (i.e., the price at time $t+1$ equals the price at time $t$ ), the two-dimensional system that characterises the dynamics of this simple duopolistic market is the following:

$$
\left\{\begin{array}{l}
p_{H}(t+1)=p_{H}(t)+\alpha_{H} p_{H}(t) \frac{\partial \Pi_{H}(t)}{\partial p_{H}(t)} . \\
p_{L}(t+1)=p_{L}(t)
\end{array}\right.
$$

Using Eq. (7.1) to substitute out for $\partial \Pi_{H}(t) / \partial p_{H}(t)$ into the first equation of (10), and Eq. (8.2) to substitute out into the right-hand side of the second equation of (10), we get:

$$
\left\{\begin{array}{l}
p_{H}(t+1)=p_{H}(t)+\alpha_{H} p_{H}(t)\left(b-\frac{2 p_{H}(t)-p_{L}(t)}{u_{H}-u_{L}}\right) \\
p_{L}(t+1)=\frac{1}{2}\left[p_{H}(t)-a\left(u_{H}-u_{L}\right)\right]
\end{array} .\right.
$$

Equilibrium implies that $p_{H}(t+1)=p_{H}(t)=p_{H}$ and $p_{L}(t+1)=p_{L}(t)=p_{L}$. Therefore, the dynamic system defined by (11) can be reduced to:

$$
\left\{\begin{array}{l}
\alpha_{H} p_{H}\left(b-\frac{2 p_{H}-p_{L}}{u_{H}-u_{L}}\right)=0 \\
p_{L}-\frac{1}{2}\left[p_{H}-a\left(u_{H}-u_{L}\right)\right]=0
\end{array} .\right.
$$

The unique interior fixed point $E_{B H / N L}^{C M}=\left(p^{*}{ }_{H}, p^{*}{ }_{L}\right)$ of the dynamic system defined by Eq. (11) is determined by the following non-negative solution of Eq. (12), that is:

$$
E_{B H / N L}^{C M}=\left(p^{*}{ }_{H}, p^{*}{ }_{L}\right)=\left(\frac{1}{3}(2 b-a)\left(u_{H}-u_{L}\right), \frac{1}{3}(b-2 a)\left(u_{H}-u_{L}\right)\right),
$$


where $E_{B H / N L}^{C M}$ stands for "covered market", which represents the pure strategy Nash equilibrium of the model. From Eq. (13.1), we note that in equilibrium $p^{*}{ }_{H}-p^{*}{ }_{L}=\frac{1}{3}(a+b)\left(u_{H}-u_{L}\right)$, so that $\bar{\phi}=\frac{a+b}{3}$. Then,

Corollary 1. Under the hypothesis of covered market, the consumer type indifferent between purchasing products of high or low quality, exclusively depends on the parameters that characterise the extent of population heterogeneity.

Proof. The proof follows immediately by looking at the equilibrium values of $\bar{\phi}$ under the hypothesis of covered market. Q.E.D.

Furthermore, outputs and profits at the equilibrium point are given by:

$$
\begin{gathered}
D^{*}{ }_{H}=\frac{2 b-a}{3}, \quad D^{*}=\frac{b-2 a}{3}, \\
\Pi_{H}^{*}=\frac{(2 b-a)^{2}\left(u_{H}-u_{L}\right)}{9}, \quad \Pi_{L}^{*}=\frac{(b-2 a)^{2}\left(u_{H}-u_{L}\right)}{9} .
\end{gathered}
$$

Notice that profits of both firms reduce when: $(i)$ the quality differential, $u_{H}-u_{L}$, reduces, and (ii) for every $b$, the value of the parameter $a$ increases.

In order to investigate the local stability properties of the fixed point (13.1) of the twodimensional system (11), we build on the Jacobian matrix $J$ evaluated at $E_{B H / N L}^{C M}$, that is:

$$
J_{B H / N L}^{C M}=\left(\begin{array}{ll}
J_{11} & J_{12} \\
J_{21} & J_{22}
\end{array}\right)=\left(\begin{array}{cc}
1-\frac{2}{3} \alpha_{H}(2 b-a) & \frac{1}{3} \alpha_{H}(2 b-a) \\
\frac{1}{2} & 0
\end{array}\right) .
$$

where $J_{i i}=\partial p_{i}(t+1) / \partial p_{i}(t)$ and $J_{i j}=\partial p_{i}(t+1) / \partial p_{j}(t)$ are evaluated at $E_{B H / N L}^{C M}$, Therefore, the trace and determinant of (14) are respectively given by:

$$
\begin{gathered}
T:=\operatorname{Tr}\left(J_{B H / N L}^{C M}\right)=J_{11}+J_{22}=1-\frac{2}{3} \alpha_{H}(2 b-a), \\
D:=\operatorname{Det}\left(J_{B H / N L}^{C M}\right)=J_{11} J_{22}-J_{12} J_{21}=-\frac{1}{6} \alpha_{H}(2 b-a)<0 .
\end{gathered}
$$

The characteristic polynomial of (14) can then be written as follows:

$$
G(\lambda)=\lambda^{2}-T \lambda+D
$$

with the discriminant being determined by $Q:=T^{2}-4 D=\left[1-\frac{2}{3} \alpha_{H}(2 b-a)\right]^{2}+\frac{1}{6} \alpha_{H}(2 b-a)>0$. Since $Q$ is positive, the existence of complex eigenvalues of $J_{B H / N L}^{C M}$ is prevented.

As is known, bifurcation theory describes the way the topological features of a dynamic system (such as the number of stationary points or their stability) vary as some parameter values are continuously changed. In particular, for the system in two dimensions determined by (11), the stability conditions ensuring that both eigenvalues remain within the unit circle are: 


$$
\left\{\begin{array}{l}
\text { (i) } \quad F:=1+T+D=2-\frac{5}{6} \alpha_{H}(2 b-a)>0 \\
\text { (ii) } \quad T C:=1-T+D=\frac{1}{2} \alpha_{H}(2 b-a)>0 \\
\text { (iii) } \quad H:=1-D=1+\frac{1}{6} \alpha_{H}(2 b-a)>0
\end{array} .\right.
$$

The violation of any single inequality in (18), with the other two being simultaneously fulfilled leads to: ( $i$ ) a flip or period-doubling bifurcation (a real eigenvalue that passes through -1 ) when $F=0$; (ii) a fold or transcritical bifurcation (a real eigenvalue that passes through +1 ) when $T C=0$; (iii) a Neimark-Sacker bifurcation (i.e., the modulus of a complex eigenvalue pair that passes through 1) when $H=0$, namely $\operatorname{Det}(J)=1$ and $|\operatorname{Tr}(J)|<2$.

From (18) it is clear that conditions (ii) and (iii) are always fulfilled for any $a \in[0, b / 2)$, while condition (i) can be violated. The existing literature on dynamic oligopolies (see, amongst others, Bischi et al., 1998, 1999; Bischi and Naimzada, 2000; Tramontana, 2010) has shown that the coefficient $\alpha$ (when at least one of the two players has bounded rational expectations) plays an important role in determining both the local and global stability properties of a two-dimensional map. In particular, if we refer to the dynamics around the equilibrium, a rise in $\alpha$ (ceteris paribus as regards marginal profits) increases the reaction of the bounded rational firm to a rise in its competitor's control variable, and then it acts as a destabilising device. This being said, the system defined by Eq. (11) that characterises the dynamics of a Bertrand duopoly with vertical differentiation, shows the same properties as regards the role played by $\alpha$ on local stability of a fixed point of those described by the existing literature. ${ }^{5}$ However, at the best of our knowledge, nobody has inquired about the dynamic effects of the parameters that capture both the degree of population heterogeneity and quality differential between products $H$ and $L$. This is the main feature that distinguishes the present paper with respect to the existing literature on dynamic oligopolies. In particular, in what follows we choose $a$ as the bifurcation parameter. In other words, for any given value of both $\alpha_{H}$ and $b$, we let $a$ vary within its domain if definition defined by Eq. (2), and study the stability properties of $E_{B H / N L}^{C M}$ when a reduces (i.e., the extent of consumers' heterogeneity increases).

As can be seen by looking at the map defined by Eq. (11), a reduction in $a$ (ceteris paribus) causes an increase (of an amount equal to half the quality differential) in the price set by the naïve firm to maximise profits, and this in turn implies, as an indirect effect, a rise in marginal profits of the bounded rational firm. Then, firm $H$ increases its price by the term $\frac{\alpha_{H} p_{H}(t)}{u_{H}-u_{L}}$, as a reaction. Therefore, a rise in the extent of consumers' heterogeneity unambiguously acts as an incentive for the bounded rational firm to increase its price, because of a twofold effect: $(i)$ a rise in its competitor's price (firm $L$ ), and (ii) a rise its marginal profits. This can produce relevant effects on stability of the fixed point, as will be clear below.

Now, define

\footnotetext{
${ }^{5}$ It is important to note, by looking at Eq. (10), that when the coefficient $\alpha$ tends to zero, the bounded rational firm does not adjust its production over time, i.e. there is no strategic interaction in such a case. This implies that the bounded rational firm does not behave as if it were naïve when $\alpha=0$. The naïve firm in fact uses the available information through the reaction function (market demand) to behave optimally over time. The bounded rational firm, instead, adjust its prices over time on the basis of its marginal profits. When both firms are naïve, the Nash equilibrium is stable (see Theocharis, 1960).
} 


$$
a_{B H / N L}=\frac{10 \alpha_{H} b-12}{5 \alpha_{H}}
$$

and

$$
\begin{aligned}
& \alpha_{1}=\frac{6}{5 b}, \\
& \alpha_{2}=\frac{8}{5 b},
\end{aligned}
$$

as the flip bifurcation value of $a$ in the case $\mathrm{BH} / \mathrm{NL}$, where $\lim _{\alpha \rightarrow+\infty} a_{B H / N L}=2 b$, and two threshold values of the speed of adjustment $\alpha$, where $\alpha_{2}>\alpha_{1}$, which are the roots for $\alpha$ obtained by equating Eq. (19) to zero and $b / 2$, respectively, i.e., the boundaries of the domain of definition of $a$. Then, from (18)-(21) we have the following proposition.

Proposition 1. (1) Let $0<\alpha<\alpha_{1}$ hold. Then, the Nash equilibrium $E_{B H / N L}^{C M}$ of the twodimensional system (11) is locally asymptotically stable for any $a \in[0, b / 2)$. (2) Let $\alpha_{1} \leq \alpha<\alpha_{2}$ hold. Then, $E_{B H / N L}^{C M}$ is locally asymptotically stable for $b / 2>a>a_{B H / N L}$, it undergoes a flip bifurcation at $a=a_{B H / N L}$, while becoming locally unstable for $a_{B H / N L}>a>0$. (3) Let $\alpha \geq \alpha_{2}$ hold. Then, the $E_{B H / N L}^{C M}$ is locally unstable for any $a \in[0, b / 2)$.

Proof. Since $a_{B H / N L}<0$ for any $0<\alpha<\alpha_{1}$, then $F>0$ for any $a \in[0, b / 2)$. This proves point (1). Since $0 \leq a_{B H / N L}<b / 2$ for any $\alpha_{1} \leq \alpha<\alpha_{2}$, then $F>0$ for any $b / 2>a>a_{B H / N L}, F=0$ if and only if $a=a_{B H / N L}$ and $F<0$ for any $a_{B H / N L}>a>0$. This proves point (2). Since $a_{B H / N L} \geq b / 2$ for any $\alpha \geq \alpha_{2}$, then $F<0$ for any $a \in[0, b / 2)$. This proves point (3). Q.E.D.

Proposition 1 reveals (under covered market) the importance of the parameter that defines the lower bound of the consumers' type range in determining local stability outcomes, while also showing that the quality differential between products $H$ and $L$ does not matter for stability. This is due to the fact that the equilibrium value of the consumer's type indifferent between purchasing products of high and low quality $\left(\bar{\phi}=\frac{a+b}{3}\right)$ exclusively depends on $a$ and $b$. Indeed, for any given value of $b$ the lower $a$, the higher the extent of consumer's heterogeneity, and the higher both the marginal profit and reaction of the bounded rational firm to a rise in its competitor's price. This, in turn, causes a destabilising effect when $\alpha$ is included in an intermediate range of values. Proposition 1, in fact, also shows the usual effect played by $\alpha$ on local stability: the higher is such a parameter, the more likely a higher degree of population heterogeneity acts as a destabilising device.

\subsection{Covered market: case $N H / B L$}

In this section we assume that firm $H$ has naïve expectations (NH), while firm $L$ has bounded rational expectations (BL) and then only the latter firm uses information on its current profit to increase or decrease prices at time $t+1$ according to the adjustment process:

$$
p_{L}(t+1)=p_{L}(t)+\alpha_{L} p_{L}(t) \frac{\partial \Pi_{L}(t)}{\partial p_{L}(t)},
$$

where $\alpha_{L}>0$. Therefore, the two-dimensional system that characterises the dynamics of the economy becomes the following: 


$$
\left\{\begin{array}{l}
p_{H}(t+1)=p_{H}(t) \\
p_{L}(t+1)=p_{L}(t)+\alpha_{L} p_{L}(t) \frac{\partial \Pi_{L}(t)}{\partial p_{L}(t)} .
\end{array}\right.
$$

By using Eqs (7.2), (8.1) and (23) we get:

$$
\left\{\begin{array}{l}
p_{H}(t+1)=\frac{1}{2}\left[p_{L}(t)+b\left(u_{H}-u_{L}\right)\right] \\
p_{L}(t+1)=p_{L}(t)+\alpha_{L} p_{L}(t)\left(\frac{p_{H}(t)-2 p_{L}(t)}{u_{H}-u_{L}}-a\right)
\end{array}\right.
$$

From Eq. (24) it is clear that, different from the BH/NL case, a reduction in $a$ (ceteris paribus) does not cause any effects on the price set by the naïve player (firm $H$ ), while determining a rise in the marginal profit of the bounded rational player (firm $L$ ), which in turn, causes an increase in its price of an amount exactly equal to $\alpha_{L} p_{L}(t)$. Therefore, analogously to the $\mathrm{BH} / \mathrm{NL}$ case, under $\mathrm{NH} / \mathrm{BL}$ a rise in the extent of consumers' heterogeneity unambiguously acts as an incentive for the bounded rational firm to increase its price. In this case, however, the economic reason why we observe such an increase is exclusively due to the rise in its marginal profits. Therefore, the extent of the rise in the price of the bounded rational firm under both $\mathrm{BH} / \mathrm{NL}$ and $\mathrm{NH} / \mathrm{BL}$ expectations is different when $a$ reduces. This (i) leads us to expect different stability effects as long as $a$ changes in the two cases, and (ii) makes clear the importance of the assumption heterogeneous expectations in a duopoly model with vertical differentiation and different consumers' tastes.

We now turn the equilibrium and local stability analyses. Equilibrium implies that $p_{H}(t+1)=p_{H}(t)=p_{H}$ and $p_{L}(t+1)=p_{L}(t)=p_{L}$. Then, the dynamic system defined by (24) can be reduced to:

$$
\left\{\begin{array}{l}
p_{H}-\frac{1}{2}\left[p_{L}+b\left(u_{H}-u_{L}\right)\right]=0 \\
\alpha_{L} p_{L}\left(\frac{p_{H}-2 p_{L}}{u_{H}-u_{L}}-a\right)=0
\end{array} .\right.
$$

The unique non-negative fixed point $E_{N H / B L}^{C M}=\left(p^{*}{ }_{H}, p^{*}{ }_{L}\right)$ of the dynamic system defined by Eq. (24) is determined by the following non-negative solution of Eq. (25), that is:

$$
E_{N H / B L}^{C M}=\left(p^{*}{ }_{H}, p^{*}{ }_{L}\right)=\left(\frac{1}{3}(2 b-a)\left(u_{H}-u_{L}\right), \frac{1}{3}(b-2 a)\left(u_{H}-u_{L}\right)\right) .
$$

It should be noted that the different type of expectation formation mechanisms is not relevant for the equilibrium outcomes of prices, outputs and profits of both firms, while playing a crucial role for stability, as can be seen below. Indeed, by comparing Eqs. (13.1) and (26) it is easy to see that $E_{B H / N L}^{C M}=E_{N H / B L}^{C M}$.

In order to investigate the local stability properties of the fixed point (26) of the twodimensional system (24), we build on the Jacobian matrix $J$ evaluated at $E_{N H / B L}^{C M}$, that is:

$$
J_{N H / B L}^{C M}=\left(\begin{array}{ll}
J_{11} & J_{12} \\
J_{21} & J_{22}
\end{array}\right)=\left(\begin{array}{cc}
0 & \frac{1}{2} \\
\frac{1}{3} \alpha_{L}(b-2 a) & 1-\frac{2}{3} \alpha_{L}(b-2 a)
\end{array}\right) .
$$

where $J_{i i}=\partial p_{i}(t+1) / \partial p_{i}(t)$ and $J_{i j}=\partial p_{i}(t+1) / \partial p_{j}(t)$ evaluated at $E_{N H / B L}^{C M}$, whose trace and determinant are given by: 


$$
\begin{gathered}
T:=\operatorname{Tr}\left(J_{N H / B L}^{C M}\right)=J_{11}+J_{22}=1-\frac{2}{3} \alpha_{L}(b-2 a), \\
D:=\operatorname{Det}\left(J_{N H / B L}^{C M}\right)=J_{11} J_{22}-J_{12} J_{21}=-\frac{1}{6} \alpha_{L}(b-2 a)<0 .
\end{gathered}
$$

Therefore, the characteristic polynomial of (27) is:

$$
Z(\lambda)=\lambda^{2}-T \lambda+D
$$

with its discriminant being determined by $P:=T^{2}-4 D=\left[1-\frac{2}{3} \alpha_{L}(b-2 a)\right]^{2}+\frac{1}{6} \alpha_{L}(b-2 a)>0$. Since the discriminant is positive, the existence of complex eigenvalues of $J_{N H / B L}^{C M}$ is prevented.

The stability conditions for the system in two-dimension (24) are the following:

$$
\left\{\begin{array}{l}
\text { (i) } \quad F:=1+T+D=2-\frac{5}{6} \alpha_{L}(b-2 a)>0 \\
\text { (ii) } \quad T C:=1-T+D=\frac{1}{2} \alpha_{L}(b-2 a)>0 \\
\text { (iii) } \quad H:=1-D=1+\frac{1}{6} \alpha_{L}(b-2 a)>0
\end{array} .\right.
$$

Now, define

$$
\begin{gathered}
a_{N H / B L}=\frac{5 \alpha_{L} b-12}{10 \alpha_{L}}, \\
\alpha_{3}=\frac{12}{5 b},
\end{gathered}
$$

as the flip bifurcation value of $a$ in the case NH/BL and a threshold value of the speed of adjustment $\alpha$, which is the unique root for $\alpha$ obtained by equating Eq. (32) to zero. Note that in this case $a_{N H / B L} \rightarrow b / 2$ when $\alpha \rightarrow+\infty$, and $\alpha_{3}>\alpha_{2}>\alpha_{1}$. Then, from (31)-(33) we have the following proposition.

Proposition 2. (1) Let $0<\alpha<\alpha_{3}$ hold. Then, the Nash equilibrium $E_{N H / B L}^{C M}$ of the twodimensional system (24) is locally asymptotically stable for any $a \in[0, b / 2)$. (2) Let $\alpha \geq \alpha_{3}$ hold. Then, $E_{N H / B L}$ is locally asymptotically stable for any $b / 2>a>a_{N H / B L}$, it undergoes flip bifurcation at $a=a_{N H / B L}$, while becoming locally unstable for any $a_{N H / B L}>a>0$.

Proof. Since $a_{N H / B L}<0$ for any $0<\alpha<\alpha_{3}$, then $F>0$ for any $a \in[0, b / 2)$. This proves point (1). Since $0 \leq a_{N H / B L}<b / 2$ for any $\alpha \geq \alpha_{3}$, then $F>0$ for any $b / 2>a>a_{N H / B L}, F=0$ if and only if $a=a_{N H / B L}$ and $F<0$ for any $a_{N H / B L}>a>0$. This proves point (2). Q.E.D.

Notice that the conditions for stability in both cases of BH/NL and NH/BL (see Eqs. 18 and 31) depend on the speed of adjustment, $\alpha_{L}$ and $\alpha_{H}$, and the parameters that reveal the difference in the degree of heterogeneity of population, $a$ and $b$, while being independent of product quality differential, $u_{H}-u_{L}$. However, Proposition 2 reveals the importance of the hypothesis of begin alternatively bounded rational for firms $H$ and $L$. In fact, under NH/BL expectations a reduction in $a$ is neutral on $p_{H}$, so that the intensity of the rise in marginal profits experienced by the bounded rational firm $(L)$ is now lower than under BH/NL, ceteris 
paribus as regards $\alpha$. Then, the destabilising effects of a rise in consumer's heterogeneity is weaker in the $\mathrm{NH} / \mathrm{BL}$ case than in the $\mathrm{BH} / \mathrm{NL}$ one.

We now compare, in the case of covered market, the stability-instability regions in the $\mathrm{BH} / \mathrm{NL}$ and $\mathrm{NH} / \mathrm{BL}$ cases by assuming $\alpha_{H}=\alpha_{L}=\alpha$. The results are summarised in the proposition that follows.

Proposition 3. The parametric stability region of $E_{B H / N L}^{C M}=E_{N H / B L}^{C M}$ is larger under $N H / B L$ than under $B H / N L$ when the market is covered.

Proof. Since from Eqs. (19) and (32) we get $a_{N H / B L}<a_{B H / N L}$ for any $\alpha>\alpha_{1}\left(\alpha_{H}=\alpha_{L}=\alpha\right)$, then Proposition 3 follows immediately. Q.E.D.

Figure 1 shows, in a stylised way, that the stability regions (in the $(\alpha, a)$ plane) under NH/BL are larger than under $\mathrm{BH} / \mathrm{NL}$. It is also interesting to note, ceteris paribus as regards the speed of adjustment, that when the economy enters the unstable region in the case $\mathrm{BH} / \mathrm{NL}$, it is still "strongly" stable in the case NH/BL, ceteris paribus as regards the coefficient $\alpha$ that tunes the speed of adjustment of the reaction of the bounded rational firm in the dynamic game.

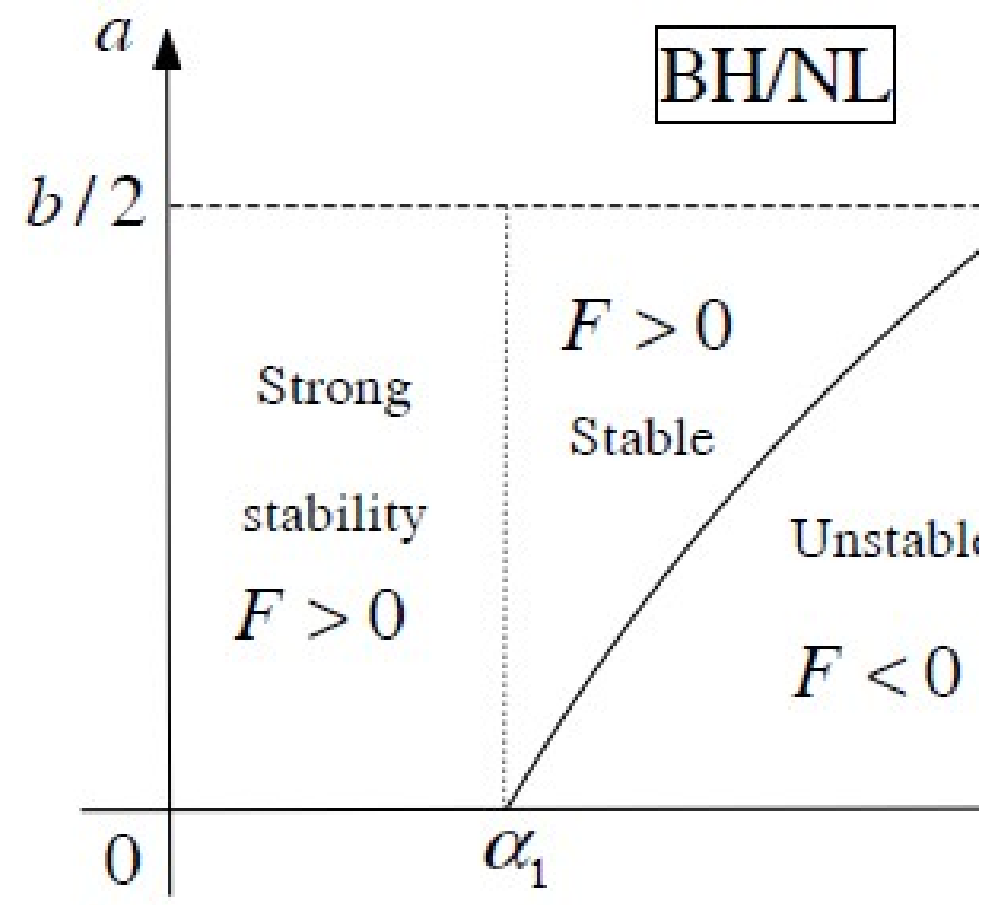

Figure 1. Covered market. Stability-instability regions in the $(\alpha, a)$ plane under $\mathrm{BH} / \mathrm{NL}$ and $\mathrm{NH} / \mathrm{BL}$ expectations. The quality differential does not matter for stability.

The following results summarise the main findings of the paper under the covered market assumption.

Result 1. Under the hypothesis of covered market, the local stability properties of the pure strategy Nash equilibrium $E_{B H / N L}^{C M}=E_{N H / B L}^{C M}$ crucially depend on the size of the consumers' type (i.e., the degree of population heterogeneity), as captured by the parameter a, while being 
independent of the level of vertical differentiation (quality) between products $H$ and $L$, as captured by the parameters $u_{H}$ and $u_{L}$. The higher the degree of population heterogeneity (low values of a), the more likely $E_{B H / N L}^{C M}=E_{N H / B L}^{C M}$ is (locally) unstable.

Result 2. Under the hypothesis of covered market, for any given value of $\alpha$, the higher the degree of population heterogeneity (low values of a), the more likely the pure strategy Nash equilibrium $E_{B H / N L}^{C M}=E_{N H / B L}^{C M}$ is (locally) unstable when firms $H$ and $L$ have BH/NL expectations than when they have $N H / B L$ expectations.

These results imply that, irrespective of the type of expectations formation mechanisms of both firms, polices that aim to increase the degree of heterogeneity amongst consumers are harmful for the (local) stability of the unique pure strategy Nash equilibrium when the market is covered, while policies that concentrate on improving or reducing the quality differential between high-quality and low-quality products are neutral on stability.

\section{Uncovered market}

In this section we follow an established literature (see, e.g., Gabszewicz and Thisse, 1979; Motta, 1993; Wauthy, 1996; Herguera et al., 2000, 2002; Liao, 2008) and assume that the market for products of high and low quality is uncovered, i.e. some consumers refrain from buying at prevailing prices. Then, under the hypotheses of both BH/NL and NH/BL expectations, we study the local stability properties of the pure strategy Nash equilibrium in such a case.

Let $\bar{\phi}$ be the index that identifies the consumer indifferent between purchasing products of high or low quality from firms $H$ and $L$ at the price $p_{H}$ and $p_{L}$, respectively. Such an index is given by Eq. (4). Let $\overline{\bar{\phi}}$ be an index that identifies consumers indifferent between purchasing products of low quality or buying anything at prevailing prices. Such an index is obtained as a solution to $U_{L}\left(\phi, p_{L}\right)=0$, i.e.

$$
\phi u_{L}-p_{L}=0
$$

Therefore, we get:

$$
\overline{\bar{\phi}}=\frac{p_{L}}{u_{L}} .
$$

Consumers identified by $\bar{\phi}<\phi<b(\overline{\bar{\phi}}<\phi<\bar{\phi})$ purchase products of high (low) quality. Indeed, those identified by $\phi<\overline{\bar{\phi}}$ refrain from buying. $\overline{\bar{\phi}}>a$, therefore, captures the case of uncovered market because there exists a portion of consumers served neither by firm $H$ not by firm $L$. Since the market is uncovered, $D_{H}\left(p_{H}, p_{L}\right)+D_{L}\left(p_{H}, p_{L}\right)<1$, with $D_{i}(\bullet)>0$ for $i=\{H, L\}$. Then, the demand functions to firms $H$ and $L$ as a function of prices are respectively given by:

$$
\begin{gathered}
D_{H}\left(p_{H}, p_{L}\right)=b-\bar{\phi}=b-\frac{p_{H}-p_{L}}{u_{H}-u_{L}}, \\
D_{L}\left(p_{H}, p_{L}\right)=\bar{\phi}-\overline{\bar{\phi}}=\frac{p_{H}-p_{L}}{u_{H}-u_{L}}-\frac{p_{L}}{u_{L}} .
\end{gathered}
$$

Therefore, profits of firms $H$ and $L$ are simply given by:

$$
\Pi_{H}\left(p_{H}, p_{L}\right)=p_{H}\left(b-\frac{p_{H}-p_{L}}{u_{H}-u_{L}}\right),
$$




$$
\Pi_{L}\left(p_{H}, p_{L}\right)=p_{L}\left(\frac{p_{H}-p_{L}}{u_{H}-u_{L}}-a\right) .
$$

The maximisation of Eqs. (37.1) and (37.2) with respect to $p_{H}$ and $p_{L}$ gives the following marginal profits:

$$
\begin{gathered}
\frac{\partial \Pi_{H}}{\partial p_{H}}=b-\frac{2 p_{H}-p_{L}}{u_{H}-u_{L}}, \\
\frac{\partial \Pi_{L}}{\partial p_{L}}=\frac{p_{H}-2 p_{L}}{u_{H}-u_{L}}-\frac{2 p_{L}}{u_{L}} .
\end{gathered}
$$

By equating Eqs. (38.1) and (38.2) to zero and solving for $p_{H}$ and $p_{L}$, we get the best reply functions of firms $H$ and $L$, respectively, that is:

$$
\begin{gathered}
\frac{\partial \Pi_{H}}{\partial p_{H}}=0 \Leftrightarrow p_{H}\left(p_{L}\right)=\frac{1}{2}\left[p_{L}+b\left(u_{H}-u_{L}\right)\right], \\
\frac{\partial \Pi_{L}}{\partial p_{L}}=0 \Leftrightarrow p_{L}\left(p_{H}\right)=\frac{u_{L}}{2 u_{H}} p_{H} .
\end{gathered}
$$

The study of the local stability properties of the unique pure strategy Nash equilibrium under $\mathrm{BH} / \mathrm{NL}$ and $\mathrm{NH} / \mathrm{BL}$ uses the same technique analysed in the previous sections.

\subsection{Uncovered market: case $B H / N L$}

The two-dimensional dynamic system when the market is uncovered and firm $H(L)$ has bounded rational (naïve) expectations is the following:

$$
\left\{\begin{array}{l}
p_{H}(t+1)=p_{H}(t)+\alpha_{H} p_{H}(t)\left(b-\frac{2 p_{H}(t)-p_{L}(t)}{u_{H}-u_{L}}\right) \\
p_{L}(t+1)=\frac{u_{L}}{2 u_{H}} p_{H}(t)
\end{array} .\right.
$$

Equilibrium implies that $p_{H}(t+1)=p_{H}(t)=p_{H}$ and $p_{L}(t+1)=p_{L}(t)=p_{L}$. In this case, the unique non-negative fixed point $E_{B H / N L}^{U M}=\left(p^{*}{ }_{H}, p^{*}{ }_{L}\right)$ of the dynamic system defined by Eq. (40), where $U M$ stands for "uncovered market", is given by:

$$
E_{B H / N L}^{U M}=\left(\frac{2 b u_{H}\left(u_{H}-u_{L}\right)}{4 u_{H}-u_{L}}, \frac{b u_{L}\left(u_{H}-u_{L}\right)}{4 u_{H}-u_{L}}\right) .
$$

Given Eq. (41), we find that $\bar{\phi}=\frac{b\left(2 u_{H}-u_{L}\right)}{4 u_{H}-u_{L}}$ and $\overline{\bar{\phi}}=\frac{b\left(u_{H}-u_{L}\right)}{4 u_{H}-u_{L}}$. Then,

Corollary 2. Under the hypothesis of uncovered market, the consumer type indifferent between purchasing products of high or low quality, $\bar{\phi}$, and the consumer type indifferent between purchasing products of low quality or refraining from buying, $\overline{\bar{\phi}}$, depend on quality differential, while being independent of the parameter $a$.

Proof. The proof follows immediately by looking at the equilibrium values of $\bar{\phi}$ and $\overline{\bar{\phi}}$ under the hypothesis of uncovered market. Q.E.D.

The stability conditions for the system in two-dimension (40) are the following: 


$$
\left\{\begin{array}{l}
\text { (i) } \quad F:=1+T+D=\frac{4 u_{H}\left(2-\alpha_{H} b\right)-u_{L}\left(2+\alpha_{H} b\right)}{4 u_{H}-u_{L}}>0 \\
\text { (ii) } \quad T C:=1-T+D=\alpha_{H} b>0 \\
\text { (iii) } \quad H:=1-D=1+\frac{\alpha_{H} b u_{L}}{4 u_{H}-u_{L}}>0
\end{array} .\right.
$$

From (42), it is easy to see that condition (ii) and (iii) are always fulfilled, while condition (i) can be violated. Now, define

$$
u_{L}^{B H / N L}=\frac{4 u_{H}\left(2-\alpha_{H} b\right)}{2+\alpha_{H} b},
$$

and

$$
\begin{gathered}
\alpha_{4}=\alpha_{1}=\frac{6}{5 b}, \\
\alpha_{5}=\frac{2}{b},
\end{gathered}
$$

as the flip bifurcation value of $u_{L}$ in the case $\mathrm{BH} / \mathrm{NL}$ and two threshold values of the speed of adjustment $\alpha$, where $\alpha_{5}>\alpha_{4}$. In particular, Eq. (43) is obtained by equating $F=0$ in (42) and then solving for $u_{L}$. Eq. (44) is computed by equating Eq. (43) to $u_{H}$ and then solving for $\alpha$, while Eq. (45) discriminates between positive and negative values of $u_{L}$. Then, from (42)(45) we have the following proposition.

Proposition 4. (1) Let $0<\alpha<\alpha_{4}$ hold. Then, the Nash equilibrium $E_{B H / N L}^{U M}$ of the twodimensional system (40) is locally asymptotically stable. (2) Let $\alpha_{4}<\alpha<\alpha_{5}$ hold. Then, $E_{B H / N L}^{U M}$ is locally asymptotically stable for any $u_{L}<u_{L}^{B H / N L}$; it undergoes a flip bifurcation at $u_{L}=u_{L}^{B H / N L}$; it is locally unstable for any $u_{L}>u_{L}^{B H / N L}$. (3) Let $\alpha>\alpha_{5}$ hold. Then, $E_{B H / N L}^{U M}$ is locally unstable.

Different from the case of covered market, Proposition 4 reveals that the quality differential matters for stability when the market is uncovered. This is due to the fact the equilibrium values of the consumers' types indifferent between purchasing products of high and low quality, $\bar{\phi}=\frac{b\left(2 u_{H}-u_{L}\right)}{4 u_{H}-u_{L}}$, and purchasing products of low quality and refraining from buying, $\overline{\bar{\phi}}=\frac{b\left(u_{H}-u_{L}\right)}{4 u_{H}-u_{L}}$, are now affected by the parameters that determine the different quality of products $H$ and $L$, while being independent of $a$. Indeed, a rise in $u_{L}$ pushes prices of firm $L$ (naïve) up. Then, marginal profits of firm $H$ (bounded rational) increase through two channels: the rise in its competitor's price and the rise in its competitor's product quality. However, a negative effect on marginal profits of firm $H$ also exists when $u_{L}$ becomes larger. Therefore, the final effect of a rise in $u_{L}$ on prices of both firms is a priori uncertain. Proposition 4 shows, however, that (ceteris paribus) an increase in product quality of firm $L$ unambiguously acts a destabilising device when the market is uncovered and $L$ is included in an intermediate range of values. This holds irrespective of the degree of heterogeneity amongst consumers.

Proof. Since $u_{L}^{B H / N L}>u_{H}>0$ for any $0<\alpha<\alpha_{4}$, then $F>0$ for any $u_{L}<u_{H}$. This proves point (1). Since $u_{H}>u_{L}^{B H / N L}>0$ for any $\alpha_{4}<\alpha<\alpha_{5}$, then $F>0$ for any $u_{L}<u_{L}^{B H / N L}, F=0$ if and 
only if $u_{L}=u_{L}^{B H / N L}$ and $F<0$ for any $u_{L}>u_{L}^{B H / N L}$. This proves point (2). Since $u_{L}^{B H / N L}<0$ for any $\alpha>\alpha_{5}$, then $F<0$ for any $u_{L}<u_{H}$. This proves point (3). Q.E.D.

\subsection{Uncovered market: case $N H / B L$}

Analogously to Section 4.1., the dynamic system that characterises the dynamics of the economy under NH/BL when the market is uncovered is the following:

$$
\left\{\begin{array}{l}
p_{H}(t+1)=\frac{1}{2}\left[p_{L}(t)+b\left(u_{H}-u_{L}\right)\right] \\
p_{L}(t+1)=p_{L}(t)+\alpha_{L} p_{L}(t)\left(\frac{p_{H}(t)-p_{L}(t)}{u_{H}-u_{L}}-\frac{p_{L}(t)}{u_{L}}\right)
\end{array}\right.
$$

The Nash equilibrium is still given by Eq. (41). The stability conditions for the system in two-dimension (46) are therefore the following:

$$
\left\{\begin{array}{l}
\text { (i) } \quad F:=1+T+D=\frac{4 u_{H}\left(4-\alpha_{L} b\right)-u_{L}\left(4+\alpha_{L} b\right)}{2\left(4 u_{H}-u_{L}\right)}>0 \\
\text { (ii) } \quad T C:=1-T+D=\frac{\alpha_{L} b}{2}>0 \\
\text { (iii) } \quad H:=1-D=1+\frac{\alpha_{L} b u_{L}}{2\left(4 u_{H}-u_{L}\right)}>0
\end{array} .\right.
$$

From (47), it is easy to see that condition (ii) and (iii) are always fulfilled, while condition (i) can be violated. Now, define

$$
u_{L}^{N H / B L}=\frac{4 u_{H}\left(4-\alpha_{L} b\right)}{4+\alpha_{L} b}
$$

and

$$
\begin{gathered}
\alpha_{6}=\alpha_{3}=\frac{12}{5 b}, \\
\alpha_{7}=\frac{4}{b},
\end{gathered}
$$

as the flip bifurcation value of $u_{L}$ in the case NH/BL and two threshold values of the speed of adjustment $\alpha$, where $\alpha_{7}>\alpha_{6}$. Eqs. (48)-(50) are the analogous of Eqs. (43)-(45). The following proposition, therefore, holds.

Proposition 5. (1) Let $0<\alpha<\alpha_{6}$ hold. Then, the Nash equilibrium $E_{N H / B L}^{U M}$ of the twodimensional system (46) is locally asymptotically stable. (2) Let $\alpha_{6}<\alpha<\alpha_{7}$ hold. Then, $E_{N H / B L}^{U M}$ is locally asymptotically stable for any $u_{L}<u_{L}^{N H / B L}$; it undergoes a flip bifurcation at $u_{L}=u_{L}^{N H / B L}$; it is locally unstable for any $u_{L}>u_{L}^{N H / B L}$. (3) Let $\alpha>\alpha_{7}$ hold. Then, $E_{N H / B L}^{U M}$ is locally unstable.

Proof. Since $u_{L}^{N H / B L}>u_{H}>0$ for any $0<\alpha<\alpha_{6}$, then $F>0$ for any $u_{L}<u_{H}$. This proves point (1). Since $u_{H}>u_{L}^{N H / B L}>0$ for any $\alpha_{6}<\alpha<\alpha_{7}$, then $F>0$ for any $u_{L}<u_{L}^{N H / B L}, F=0$ if and only if $u_{L}=u_{L}^{N H / B L}$ and $F<0$ for any $u_{L}>u_{L}^{N H / B L}$. This proves point (2). Since $u_{L}^{N H / B L}<0$ for any $\alpha>\alpha_{7}$, then $F<0$ for any $u_{L}<u_{H}$. This proves point (3). Q.E.D. 
Arguments similar to those used to explain Proposition 4 apply to Proposition 5, which refers to the case NH/BL. We now compare, in the case of uncovered market, the stability-instability regions under $\mathrm{BH} / \mathrm{NL}$ and $\mathrm{NH} / \mathrm{BL}$ expectations by assuming $\alpha_{H}=\alpha_{L}=\alpha$. The results are summarised in the following proposition.

Proposition 6. The parametric stability region of $E_{B H / N L}^{U M}=E_{N H / B L}^{U M}$ is larger under $N H / B L$ than under BH/NL when the market is uncovered.

Proof. Since from Eqs. (19) and (32) we get $u_{L}^{N H / B L}<u_{L}^{B H / N L}$ for any configuration of economically meaningful parameter values, then Proposition 6 follows immediately. Q.E.D.

Figure 2 shows in a stylised way that the stability-instability regions in the $\left(\alpha, u_{L}\right)$ plane are larger under $\mathrm{NH} / \mathrm{BL}$ than under $\mathrm{BH} / \mathrm{NL}$, when the market is uncovered.

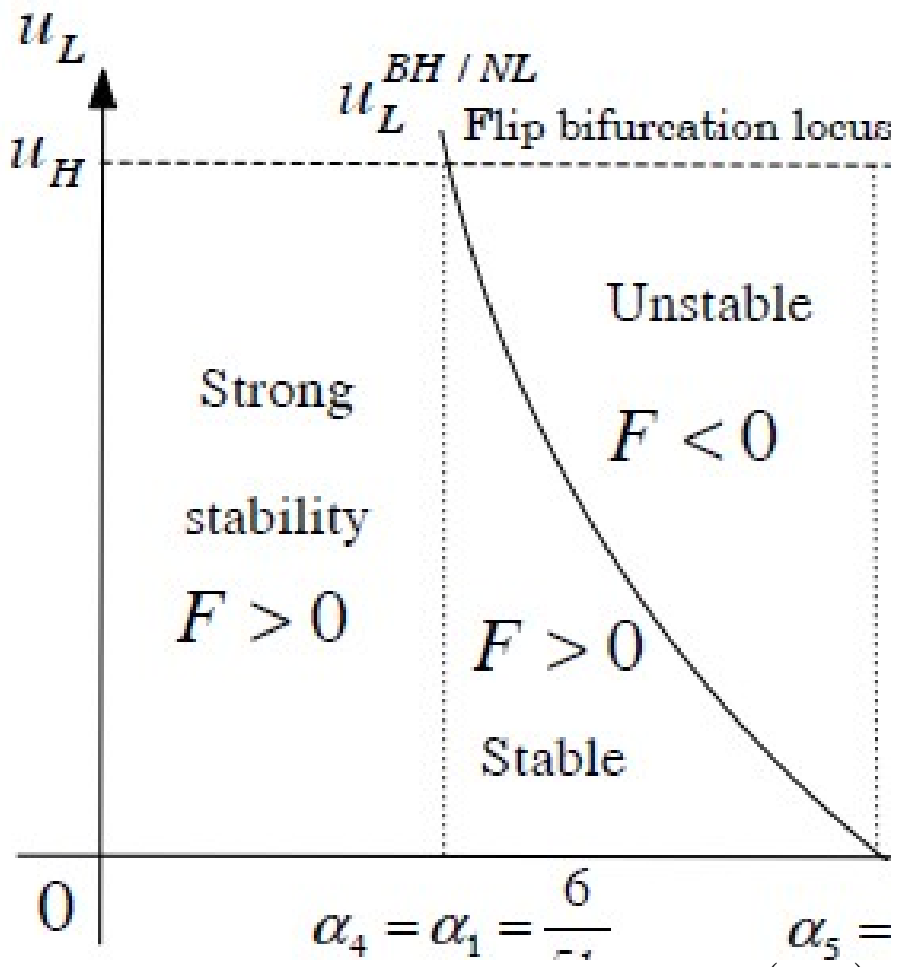

Figure 2. Uncovered market. Stability-instability regions in the $\left(\alpha, u_{L}\right)$ plane under $\mathrm{BH} / \mathrm{NL}$ and NH/BL expectations. The quality differential matters for stability.

The following results summarise the main findings of the paper under the uncovered market assumption.

Result 3. Under the hypothesis of uncovered market, the local stability properties of the pure strategy Nash equilibrium $E_{B H / N L}^{U M}=E_{N H / B L}^{U M}$ crucially depend on the quality differential between products $H$ and $L$, while being independent of the parameter a. The higher $u_{L}$, the more likely $E_{B H / N L}^{U M}=E_{N H / B L}^{U M}$ is (locally) unstable. 
Result 4. Under the hypothesis of uncovered market, for any given value of $\alpha$, the higher $u_{L}$, the more likely the pure strategy Nash equilibrium $E_{B H / N L}^{U M}=E_{N H / B L}^{U M}$ is (locally) unstable when firms $H$ and $L$ have $B H / N L$ expectations than when they have $N H / B L$ expectations.

These results imply that, irrespective of the type of expectations formation mechanisms, polices that aim to reduce the quality differential (by increasing $u_{L}$ for any given value of $u_{H}$ ) are harmful to the local stability of prices when the market is uncovered, while policies that concentrate to improve the degree of population heterogeneity through a reduction in $a$ are neutral.

\section{Conclusions}

This study originates from the increasing interest for a refined analysis in the nonlinear oligopoly literature under naïve expectations (e.g., Tramontana et al., 2009), bounded rational expectations (e.g., Tramontana, 2010) and, more in general, expectations formation mechanisms based on adaptive rules (e.g., Agliari et al., 2006). The novelty of this paper is the analysis of local stability in a duopoly game with price competition, vertical differentiation and heterogeneous expectations under the assumptions of both covered and uncovered market.

The assumption of heterogeneous expectations is usual in the literature on nonlinear oligopolies. An example is Fanti and Gori (2012), where a Cournot duopoly with horizontal differentiation is studied to show that the relative degree of substitutability may cause the appearance of flip bifurcations and complex dynamics. The purpose of the this study is to complement that paper with the analysis of a Bertrand duopoly with vertical differentiation.

We have shown that an increase (resp. reduction) in the extent of consumer's heterogeneity (resp. quality differential) acts as a destabilising device when the market is covered (resp. uncovered). Moreover, numerical experiments have revealed that complex dynamics can also be observed.

\section{Acknowledgements}

The authors gratefully acknowledge three anonymous reviewers for valuable comments on an earlier draft. The usual disclaimer applies.

\section{Appendix A. Endogenous fluctuations (covered market)}

In this appendix we show with numerical experiments that endogenous fluctuations can occur when $a$ reduces (covered market). The parameter values are: $b=1, \alpha=4, u_{H}=2$ and $u_{L}=1$. Then, $a_{B H / N L}=1.4, \alpha_{1}=6 / 5$ and $\alpha_{2}=8 / 5(\mathrm{BH} / \mathrm{NL})$, and $a_{N H / B L}=0.2$ and $\alpha_{3}=12 / 5(\mathrm{NH} / \mathrm{BL})$. Under this parameter constellation, we find $a_{B H / N L}>b / 2$ so that the Nash equilibrium $E_{B H / N L}^{C M}=E_{N H / B L}^{C M}$ in the $\mathrm{BH} / \mathrm{NL}$ model is unstable and trajectories are non-convergent for any $a \in[0,1 / 2)$. With regards to the NH/BL model, $4=\alpha>\alpha_{3}$ implying that $E_{B H / N L}^{C M}=E_{N H / B L}^{C M}$ is stable or unstable depending on the relative size of $a$. To this purpose, Figures A.1.a and A.1.b show the bifurcation diagrams for $a$ under NH/BL, and depict the limit point of $p_{L}$ and $p_{H}$, respectively, when the initial conditions are $p_{H}(0)=0.1$ and $p_{L}(0)=0.05$. The figures reveal that the long-run values of prices increase and they are locally asymptotically stable when $a$ reduces from $1 / 2$ to 0.2 . Then, a flip bifurcation occurs at $a_{N H / B L}=0.2$. Then, a two-period 
cycle (broken off in the range $a \in(0.05776,0.05727)$ by more complicated dynamic events) emerges. As long as $a$ reduces, we observe four-period cycles, eight-period cycles, and cycles of higher periodicity when $a$ becomes lower. Figure A.2 also depicts the chaotic attractor (black-coloured) and the corresponding basin of attraction (red-coloured) for $a=0.03$.

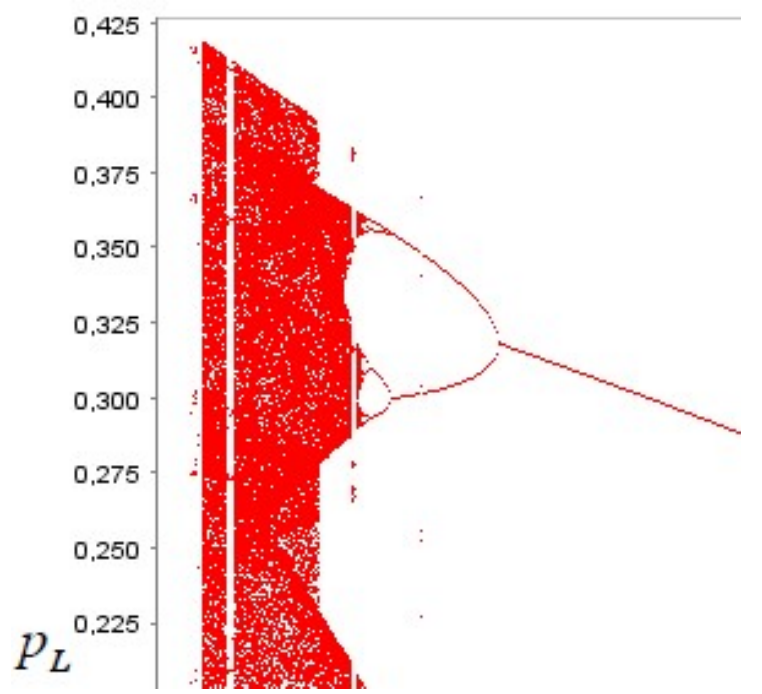

(a)

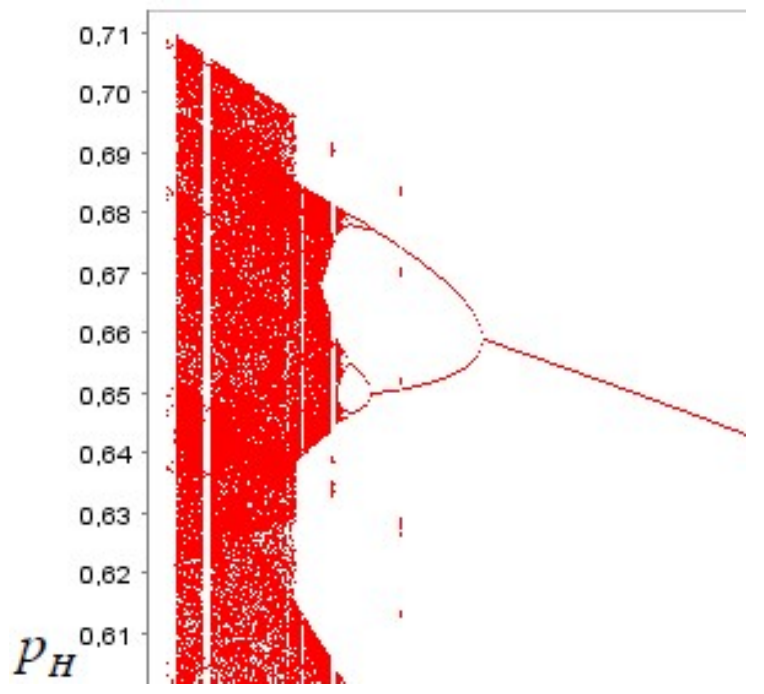

(b)

Figure A.1. Covered market. Bifurcation diagram for $a$ under NH/BL expectations. Initial conditions: $p_{H}(0)=0.1$ and $p_{L}(0)=0.05$.

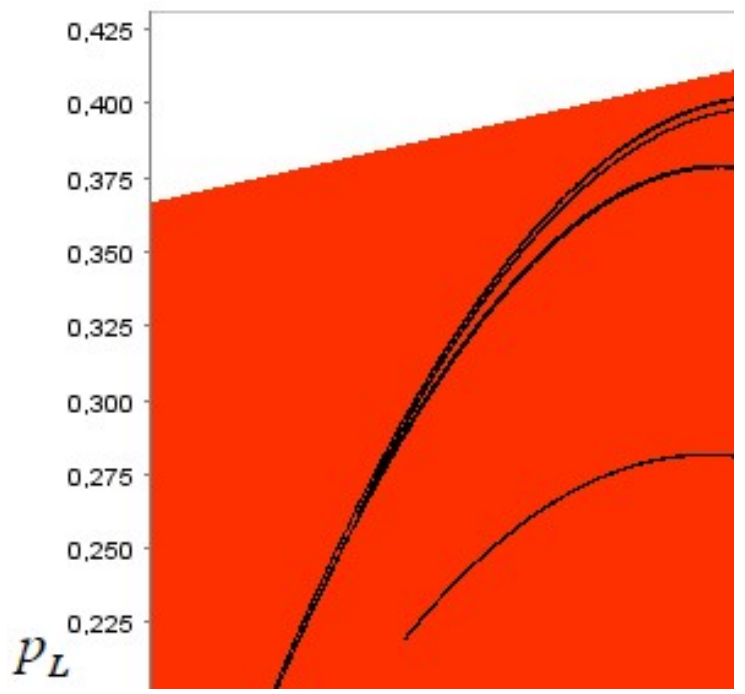

Figure A.2. Covered market. Chaotic attractor and their basic of attraction for $a=0.03$ under $\mathrm{NH} / \mathrm{BL}$ expectations.

\section{Appendix B. Endogenous fluctuations (uncovered market)}

We show here that endogenous fluctuations occur when $u_{L}$ raises (uncovered market). We depict bifurcation diagrams and basins of attraction only under BH/NL expectations, since the case NH/BL shows similar dynamic events. 
The parameter set is: $b=1$ (so that $\alpha_{4}=6 / 5$ and $\alpha_{5}=2$ ) and $a=0.5$. Then, we choose $\alpha=1.9, u_{H}=2$ and let $u_{L}$ increase from 0 to 2 . These parameter values generate $u_{L}^{B H / N L}=0.2051$. We note that since $\alpha_{4}<\alpha<\alpha_{5}$, then the Nash equilibrium $E_{B H / N L}^{U M}=E_{N H / B L}^{U M}$ is locally stable or unstable depending on the relative size of $u_{L}$. Figures B.1.a and B.1.b show the bifurcation diagrams for $u_{L}$ under $\mathrm{BH} / \mathrm{NL}$, and depict the limit point of $p_{L}$ and $p_{H}$, respectively, when the initial conditions are $p_{H}(0)=0.1$ and $p_{L}(0)=0.05$. The Nash equilibrium is locally asymptotically stable when $u_{L}$ is small. A flip bifurcation occurs at $u_{L}^{B H / N L}=0.2051$. Then, a two-period cycle emerges and cycles of higher periodicity occur when $u_{L}$ becomes larger. It is interesting to note that in the long run the trend of the highquality price is monotonically decreasing, while the low-quality price increases (decreases) when the index $u_{L}$ is small (large). Figure B.2 depicts the chaotic attractor (black-coloured) and the corresponding basin of attraction (red-coloured) for $u_{L}=1.85$.

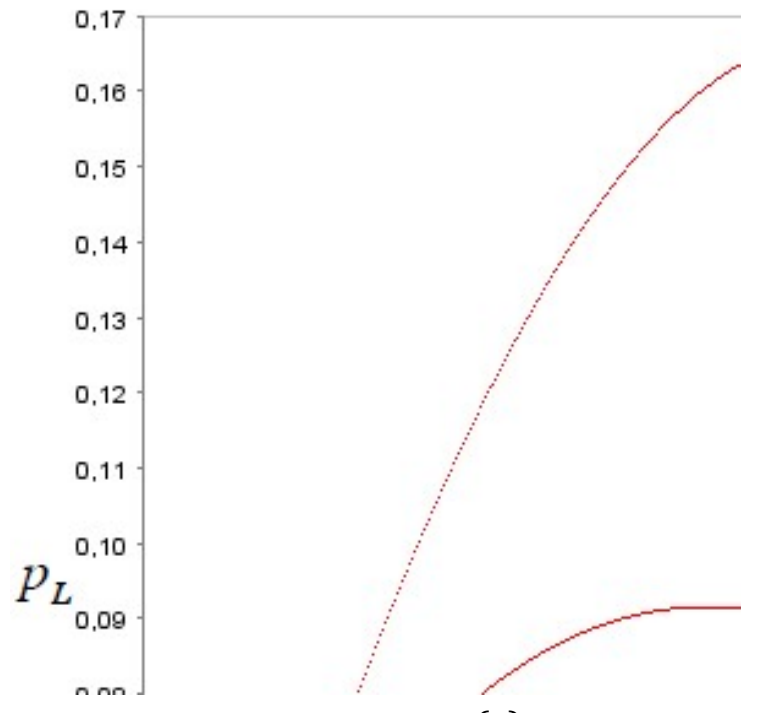

(a)

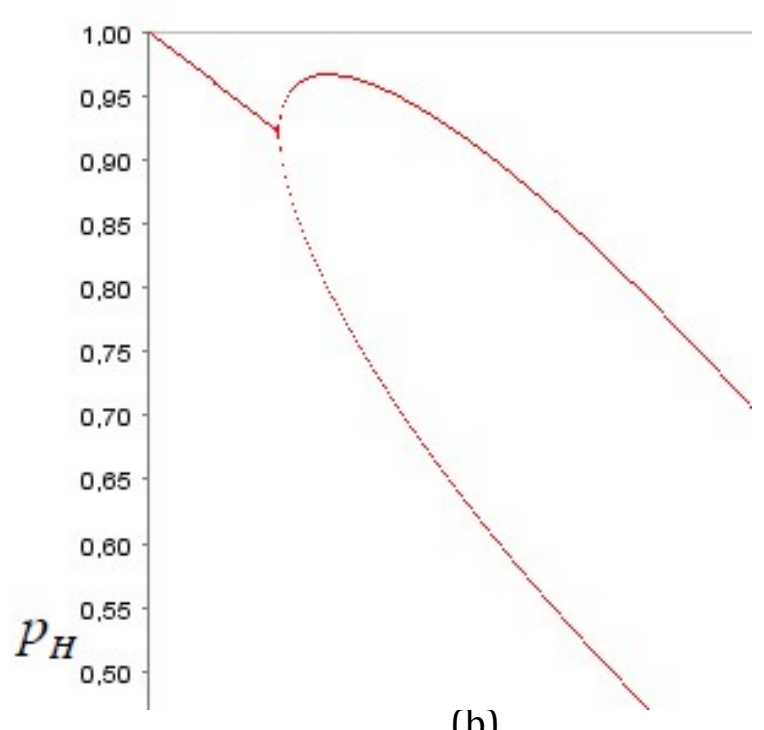

(b)

Figure B.1. Uncovered market. Bifurcation diagram for $u_{L}$ under BH/NL expectations. Initial conditions: $p_{H}(0)=0.1$ and $p_{L}(0)=0.05$.

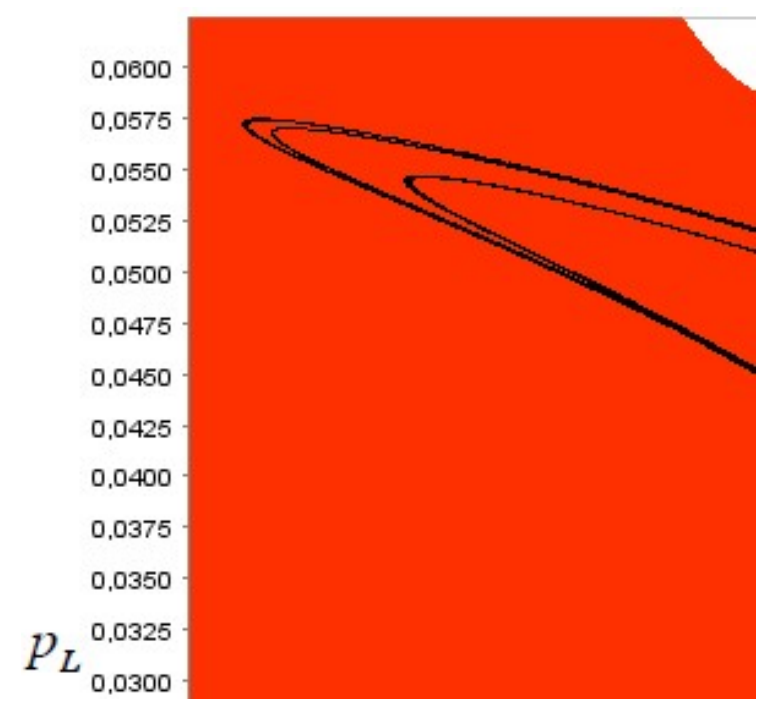


Figure B.2. Uncovered market. Chaotic attractor and their basic of attraction for $u_{L}=1.85$ under $\mathrm{BH} / \mathrm{NL}$ expectations.

\section{References}

Agiza HN, Elsadany AA (2003) Nonlinear dynamics in the Cournot duopoly game with heterogeneous players. Physica A 320:512-524

Agiza HN, Elsadany AA (2004) Chaotic dynamics in nonlinear duopoly game with heterogeneous players. Appl Math Comput 149:843-860

Agiza HN, Hegazi AS, Elsadany AA (2002) Complex dynamics and synchronization of duopoly game with bounded rationality. Math Comput Simulat 58:133-146

Agliari A, Chiarella C, Gardini L (2006) A re-evaluation of adaptive expectations in light of global nonlinear dynamic analysis. J Econ Behav Organ 60:526-552

Bertrand J (1883) Théorie mathématique de la richesse sociale. J des Savants 48:499-508

Bischi GI, Naimzada A (2000) Global analysis of a dynamic duopoly game with bounded rationality. In: Filar JA, Gaitsgory V, Mizukami K (eds) Advances in Dynamics Games and Application, vol. 5. Birkhäuser, Boston 361-385

Bischi GI, Gallegati M, Naimzada A (1999) Symmetry-breaking bifurcations and representative firm in dynamic duopoly games. Ann Oper Res 89:253-272

Bischi GI, Stefanini L, Gardini L (1998) Synchronization, intermittency and critical curves in duopoly games. Math Comput Simulat 44:559-585

Bischi GI, Chiarella C, Kopel M, Szidarovszky F (2010) Nonlinear Oligopolies. Stability and Bifurcations. Springer-Verlag, Berlin Heidelberg

Chiarella C (1986) Perfect foresight models and the dynamic instability problem from a higher viewpoint. Econ Model 3:283-292

Chiarella C (1990) The Elements of a Nonlinear Theory of Economic Dynamics. Berlin: Springer Verlag

Correa-López M, Naylor RA (2004) The Cournot-Bertrand profit differential: a reversal result in a differentiated duopoly with wage bargaining. Eur Econ Rev 48:681-696

Cournot A (1838) Recherches sur les Principes Mathématiques de la Théorie des Richessess. Hachette, Paris

Den-Haan WJ (2001) The importance of the number of different agents in a heterogeneous asset-pricing model. J Econ Dyn Control 25:721-746

Dixit AK (1979) A model of duopoly suggesting a theory of entry barriers. Bell J Econ 10:2032

Dixit AK (1986) Comparative statics for oligopoly. Int Econ Rev 27:107-122

Fanti L, Gori L (2011) The dynamics of a Bertrand duopoly with differentiated products and bounded rational firms revisited. MPRA Working Paper 33268

Fanti L, Gori L (2012) The dynamics of a differentiated duopoly with quantity competition. Econ Model 29:421-427

Gabszewicz JJ, Thisse JF (1979) Price competition, quality and income disparities. J Econ Theory 20:310-359

Häckner J (2000) A note on price and quantity competition in differentiated oligopolies. J Econ Theory 93:233-239

Herguera I, Kujal P, Petrakis E (2000) Quantity restrictions and endogenous quality choice. Int J Ind Organ 18:1259-1277

Herguera I, Kujal P, Petrakis E (2002) Tariffs, quality reversals and exit in vertically differentiated industries. J Int Econ 58:467-492

Kopel M (1996) Simple and complex adjustment dynamics in Cournot duopoly models. Chaos Soliton Fract 12:2031-2048 
Leonard D, Nishimura K (1999) Nonlinear dynamics in the Cournot model without full information. Ann Oper Res 89:165-173

Liao PC (2008) A note on market coverage in vertical differentiation models with fixed costs. B Econ Res 60:27-44

Motta M (1993) Endogenous quality choice: price vs. quantity competition. J Ind Econ 41:113-131.

Puu T (1991) Chaos in duopoly pricing. Chaos Soliton Fract 1:573-581

Puu T (1998) The chaotic duopolists revisited. J Econ Behav Organ 33:385-394

Shaked A, Sutton, J (1982) Relaxing price competition through product differentiation. Rev Econ Stud 49:3-14

Shaked A, Sutton, J (1983) Natural oligopolies. Econometrica 51:1469-1483

Singh N, Vives X (1984) Price and quantity competition in a differentiated duopoly. RAND J Econ 15:546-554

Tarola 0, Gabszewicz JJ, Laussel D (2011) To acquire, or to compete? An entry dilemma. J Ind Compet Trade 11:369-383

Theocharis RD (1960) On the stability of the Cournot solution on the oligopoly problem. Rev Econ Stud 27:133-134

Tirole J (1988) The Theory of Industrial Organization. MIT Press, Boston

Tramontana F (2010) Heterogeneous duopoly with isoelastic demand function. Econ Model $27: 350-357$

Tramontana F, Gardini L, Puu T (2009) Cournot duopoly when the competitors operate multiple production plants. J Econ Dyn Control 33:250-265

Vives X (1985) On the efficiency of Bertrand and Cournot equilibria with product differentiation. J Econ Theory 36:166-175

Wauthy X (1996) Quality choice in models of vertical differentiation. J Ind Econ 44:345-353

Zhang J, Da Q, Wang Y (2007) Analysis of nonlinear duopoly game with heterogeneous players. Econ Model 24:138-148

Zhang J, Da Q, Wang Y (2009) The dynamics of Bertrand model with bounded rationality. Chaos, Solitons and Fractals 39:2048-2055 